\title{
Application of statistical design of experiments for the optimization of floor tile glaze formulation
}

\begin{abstract}
This paper investigates the influence of the various parameters on the quality of industrial Iranian floor tile glaze by using the experimental designs analysis, Taguchi Method. A commercial grade of engobe and green body from one of the national tile companies have been used. Three factors namely: particle size of glaze slurry, sintering time and temperature were selected to identify the influence of these factors on the quality of glaze. A Taguchi L8 Orthogonal Arrays, fractional factorial design, was used to optimize experimental trials. This approach successfully categorized the effect of each variable using only 8 experimental trials and identified the most important variables affecting this glaze making process with the analysis of variance (ANOVA). The quality control tests of floor tile such as thermal shock resistance, specking resistance and surface hardness were carried out according to the existing Iranian standard. The optimized samples were obtained by factorial design analysis; taking into account coarser particle size, higher temperature and less time. The optimized sample was counter checked using Taguchi method and by selecting effective factors in high levels. It was demonstrated that, the particle size of the slurry is the only significant parameter and sample with high level in particle size and temperature of sintering is the best sample according to existing standard of floor tile.
\end{abstract}

\section{Sousan Rasouli}

Department of Nanomaterials and Nanocoatings, Institute for Color Science and Technology (ICST), Tehran, Iran

Corresponding author: Sousan Rasouli e-mail: rasouli@icrc.ac.ir

First recieved: 22.11.2016. Accepted: 28.02.2017.

\section{KEY WORDS}

Optimization, floor tile, glaze, factorial design, Taguchi

\section{Introduction}

The glaze, like the ceramic body, is made up of a series of inorganic raw materials. The main component of the glaze is silica glass as well as other elements that act as fluxes (alkalis, alkaline earths), former (boron, zinc, etc), opacities (zirconium, titanium, etc), and as coloring agents (chromium, cobalt, Manganese, etc). Although several glass-forming systems exist, ceramic glazes are almost completely based on alumina-silicate glass systems. The main glass forming oxide, silica $\left(\mathrm{SiO}_{2}\right)$ is modified by adding a range of other oxides. The modifiers act to alter thermal, chemical, and physical properties of the product, (Table 1) (Vari, 2000; Burleson, 2003).

\section{Table 1}

Common components of a ceramic glaze

\begin{tabular}{c|c|c}
\hline Glass Formers & Intermediates & Modifiers (Melters) \\
\hline $\mathrm{SiO}_{2}$ & $\mathrm{Al}_{2} \mathrm{O}_{3}$ & $\mathrm{BaO}$ \\
& $\mathrm{ZrO}_{2}$ & $\mathrm{CaO}$ \\
& $\mathrm{TiO}_{2}$ & $\mathrm{SrO}$ \\
& $\mathrm{ZnO}$ \\
& $\mathrm{PbO}$ \\
& $\mathrm{Na}_{2} \mathrm{O}$ \\
& $\mathrm{K}_{2} \mathrm{O}$ \\
& $\mathrm{Li}_{2} \mathrm{O}$ \\
& $\mathrm{Bi}_{2} \mathrm{O}_{3}$ \\
& $\mathrm{~B}_{2} \mathrm{O}_{3}$
\end{tabular}


In other ceramic processes (porcelain art ware, sanitary ware), glazes are formulated such a way that only contain crystalline, natural or synthetic raw materials, which provide the necessary oxides. However, in ceramic floor and wall tile manufactures, raw materials of a glossy nature (frits) are normally used. These are prepared from the same crystalline materials that have previously undergone heat treatment under high temperature. Glaze generally comprises one or more glass frits, filler pigments and other additives which either vitrify or sinter, depending upon the composition of the glaze and degree of firing. Raw glazes are typically composed of a mixture of finely ground insoluble beneficiated natural materials-minerals and rocks such as china clay and Nephelin Syenite. Fritted glazes are those where all or part of ingredients have been per fused and quenched to form one or more frits. A wide variety of the glazes are formulated depending on the type of product, firing temperature, and the desired effects and properties of the final product (Burleson, 2003). Recently, some studies investigated the application of design of the experiments to optimizing the glaze preparation (Ghosh, 1990; Ross, 1995; Roy, 2001; Anufrik et al., 2016). Since cost and time are two crucial parameters in industry, less cost in the least time is therefore desired. Most of researchers and companies normally use statistical methods to optimize the appropriate condition. Examples of two important design methods for process improvement are Taguchi and full Factorial designs to achieve better condition in production.

This paper aims to investigate the possibility of utilization of Taguchi method in designing optimum experimental procedure for floor Tile Glaze industries and further investigates the various parameters affecting the quality of the product.

\section{Experimental design}

\section{Taguchi method}

In 1926 British statistician R.A. Fischer began applying fractional factorial approaches to agricultural experiments. In the 1960's Professor Genichi Taguchi applied modified factorial experiment designs for characterizing manufacturing processes in his quality engineering philosophy (Castela, Fonseca \& Mantas, 2010; Reddy \& Asadi, 2011; Sharda \& Kumar, 2015).

Taguchi method is a scientifically disciplined mechanism or evaluation and implementing improvements in products, processes, materials, equipments, and facilities. These improvements are aimed at improving the desired characteristics and simultaneously reducing the number of defects by studying the key variables controlling the process and optimizing the procedure or design to yield the best results. The method is appli- cable over the wide range of engineering fields that produce raw materials, sub systems, products or professional and consumer markets. In fact, the method can be applied to any processes that manufacture be it engineering fabrication, computer-aided-design, blanking and service sector etc. There are five basic phases (Figure 1) in applying the Taguchi experimental design technique to a project. For projects in industrial settings, it is important to follow these steps closely. Phase I, experiment planning, is the most valuable. The major steps to complete an effective designed experiment are listed in the following text. The planning Phase includes step 1 through 9, the conducting phase is step 10 , and the analysis phase includes step 11 and 12.

1. State the problem(s) or area(s) of concern.

2. State the objective(s) of the experiment.

3. Select the quality characteristic and measurement system(s)

4. Select the factors that may influence the selected quality characteristics.

5. Identify control and noise factors.

6. Select levels for the factor.

7. Select the appropriate orthogonal array OA. .

8. Select the interactions that may influence the selected quality characteristics or go back to step 4 (interactive steps)

9. Assign factors to $O A$ and locate interactions.

10. Conduct tests described by trials in OA.

11. Analyze and interpret results of the experiments trials.

12. Conduct confirmation experiment.

13. Analyze the data; predict the optimum levels and performance

14. Perform the verification experiment and plan future action (Ghosh, 1990; Ross, 1995).

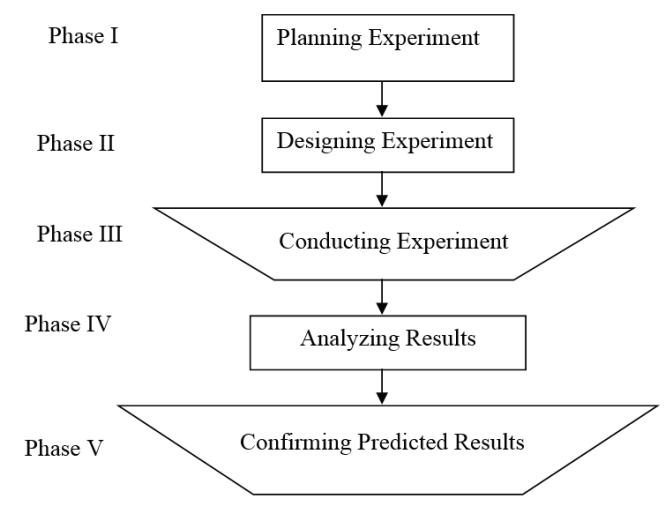

» Figure 1: Five basic phases

The word "optimization" in Taguchi method implies, "the determination of the best levels of control factors. The best levels of control factors are those that maximize the signal-to-noise ratios. The signal-to-noise ratios are log functions of desired output characteristics (Reddy \& Asadi, 2011). 


\section{Factorial designs overview}

Factorial designs allow for the simultaneous study of the effects that several factors may have on a process. When performing an experiment, varying the levels of the factors simultaneously rather than one at a time is efficient in terms of time and cost, and also allows for the study of interactions between the factors. Interactions are the driving force in many processes. Without the use of factorial experiments, important interactions may remain undetected (Feinberg, 1996; Mukerjee \& Wu, 2006; Chen et al., 2015; Smith, 2015).

\section{$2 \mathrm{k}$ full factorial design}

In his method two levels of each factor will be studied in an orthogonal, balanced, array. If there are $\mathrm{k}$ factors required to evaluate in a process, we need to run the experiment $2^{k}$ times. Each factor will have two levels, "high" and "low" levels (Feinberg, 1996).

Consider the two-level, full factorial design for three factors, namely the $2^{3}$ design. This implies eight runs (not counting replications or center point runs), full factorial in a tabular form, ( $2^{3}$ two-level design; factors $X_{1}$, $X_{2}, X_{3}$ ). This design is given by Table 2 (Feinberg, 1996).

\section{Table 2}

$2^{3}$ two-level, full factorial design table showing runs in standard order

\begin{tabular}{c|c|c|c}
\hline Run & $\mathbf{X 1}$ & $\mathbf{X 2}$ & $\mathbf{X 3}$ \\
\hline 1 & -1 & -1 & -1 \\
\hline 2 & 1 & -1 & -1 \\
\hline 3 & -1 & 1 & -1 \\
\hline 4 & 1 & 1 & -1 \\
\hline 5 & -1 & -1 & 1 \\
\hline 6 & 1 & -1 & 1 \\
\hline 7 & -1 & 1 & 1 \\
\hline 8 & 1 & 1 & 1 \\
\hline
\end{tabular}

\section{Estimate of Main Effects with calculation of main coefficients}

The effect of a factor can be defined as the average response when the factor changes from one level to another level (e.g. from high to low level) (Feinberg, 1996).

The following equations are used to calculate the coefficient of main and average factors.

$$
a_{i}=\frac{\sum_{J=1}^{N} Y_{+i}-\sum_{J=1}^{N} Y_{-i}}{N}
$$

$\mathrm{a}_{0}=\frac{\sum_{\mathrm{J}=1}^{\mathrm{N}} \mathrm{Y}_{\mathrm{i}}}{\mathrm{N}}$

where,

$Y_{i}$ : response of the experiment

$Y_{+i}$ : response of the experiment in high level

$Y_{-i}$ : response of the experiment in low level

$\mathrm{N}$ : number of the experiments

If $a_{i}>2 S E$, so this factor has a significant effect on the response and vice versa (Feinberg, 1996).

\section{Experimental procedure}

\section{Sample preparation}

Since this research is an attempt on the preparation of industrial glazes, so a commercial grade of engobe and green body from one of the national tile companies have been used. Glaze formulation is presented in Table 3.

\section{Table 3}

Chemical composition of raw materials used in opaque glaze structure (in W\%)

\begin{tabular}{c|c|c|c|c|c|c}
\hline Frit & Kaolin & Silica & K-Feldspar & Calcite & CMC & TPP \\
\hline 20 & 10 & 10 & 50 & 10 & 0.08 & 0.2 \\
\hline
\end{tabular}

Frit and the other raw materials were ground in an electric mortar (type 06, pulverisette, Germany) at $150 \mathrm{rpm}$ for 30 minutes, to provide them with appropriate fineness of grinding and were then screened by 325 and 400 mesh $(44,37 \mu \mathrm{m})$. The under sieve portion were applied directly on to the engobe green (unfired) tiles by spraying technique. After having been dried in an oven at $105^{\circ} \mathrm{C}$ for 1 hour, the glazed tiles were single fired in a laboratory electrical furnace at two different temperatures. Thermal shock resistance, specking resistance and surface hardness were tested for all of them by the National Standard Institute.

\section{Two-level full factorial design of experiments}

Individual variables (particle size of glaze slurry, particle size (PS), sintering temperature, Temp, and sintering time, $t$ ), the effects of which on properties of glaze tile were examined; change in different ranges of the parameters conformed to the orthogonal $2^{n}$ two-level factorial design, were $n=3$, of the form presented in Table 2. According to the design, 8 experiments should be preformed in which individual variables $\mathrm{a}_{1}, \mathrm{a}_{2}$ and $\mathrm{a}_{3}$ are given code values at upper $(+1)$ and lower (-1). High and low settings for each input variable were selected according to the schedule shown in Table 4. In addition, Table 5 illustrates the design of experiment using factorial method. 
Table 4

High and low Settings for the variables

\begin{tabular}{l|c|c|}
\hline Variable & Low setting & High setting \\
\hline Temperature $\left(\mathrm{TEM}^{\circ}{ }^{\circ} \mathrm{C}\right)$ & 1100 & 1150 \\
\hline Time $(\mathrm{TE}, \mathrm{min})$ & 30 & 120 \\
\hline Particle size of slurry $(\mathrm{PS}, \mu)$ & $\mathrm{X}<37$ & $44<\mathrm{X}<37$ \\
\hline
\end{tabular}

Table 5

Two-level factorial design of experiments for three variables considered in this study

\begin{tabular}{c|c|c|c}
\hline Experiment No. & TEM & TE & PS \\
\hline 1 & +1 & +1 & +1 \\
\hline 2 & -1 & +1 & +1 \\
\hline 3 & +1 & -1 & +1 \\
\hline 4 & -1 & -1 & +1 \\
\hline 5 & +1 & +1 & -1 \\
\hline 6 & -1 & +1 & -1 \\
\hline 7 & +1 & -1 & -1 \\
\hline 8 & -1 & -1 & -1 \\
\hline
\end{tabular}

\section{Taguchi design of experiments}

\section{Selection of experimental plan}

We concluded that some parameters can significantly influence the final quantitative results of floor tile glaze and the statistical design of experiments technique is highly effective for this type of evaluation used.

The experimental research allows investigating on the influence of $\mathrm{N}$ variables and the interactions. It can be further studied the effect of three parameters and two interactions which signifi- cantly affect the quality of floor tile glaze. The orthogonal Array L8 is represented in Table 6.

\section{Table 6}

L8 $\left(2^{5}\right)$ Array

\begin{tabular}{c|c|c|c|c|c|c}
\hline Run & PS & \multicolumn{1}{c}{ TEM } & \multicolumn{2}{c}{ PS $\times$ TEM TE } & \multicolumn{2}{c}{ TEM. $\times$ TE hardness } \\
\hline 1 & $X<37$ & $1100{ }^{\circ} \mathrm{C}$ & 1 & 30 & 1 & 4 \\
\hline 2 & $44<X<37$ & $11000^{\circ} \mathrm{C}$ & 1 & 120 & 2 & 4 \\
\hline 3 & $X<37$ & $1150{ }^{\circ} \mathrm{C}$ & 2 & 30 & 2 & 3 \\
\hline 4 & $44<X<37$ & $1150{ }^{\circ} \mathrm{C}$ & 2 & 120 & 1 & 4 \\
\hline 5 & $X<37$ & $1100{ }^{\circ} \mathrm{C}$ & 2 & 30 & 1 & 4 \\
\hline 6 & $44<X<37$ & $1100{ }^{\circ} \mathrm{C}$ & 2 & 120 & 2 & 5 \\
\hline 7 & $X<37$ & $1150{ }^{\circ} \mathrm{C}$ & 1 & 30 & 2 & 5 \\
\hline 8 & $44<X<37$ & $1150^{\circ} \mathrm{C}$ & 1 & 120 & 1 & 6 \\
\hline
\end{tabular}

\section{Results and discussion}

As this study investigates an industrial sample according to standard of floor tile, so response of some tests were given qualitative. The only quantifiable response is hardness, so calculations were based on this response. The response of experiments was presented in Table 7. SE (Standard Error), coefficients of main and interaction were given in Table 8.

\section{According to factorial concept if $a_{i}>2 S E$, so the influence} of the particle size of glaze slurry (variable $X_{1}$ ) in hardness of glaze has been significant. The samples 1 to 3 were not acceptable according to standard; so they were eliminated. The residual samples $(5,7)$ with low level of particle size, were also eliminated. This shows that an appropriate sample should be selected from three residual samples (4, 6 and 8$)$. Therefore, sample 4 with high level in particle size and temperature of sintering

\section{Table 7}

Predicated properties of floor tile glaze for different values of studied parameters

\begin{tabular}{|c|c|c|c|c|c|c|c|c|}
\hline \multirow{2}{*}{$\begin{array}{c}\mathrm{Y}_{4} \\
\text { Hardness }\end{array}$} & \multicolumn{2}{|c|}{$Y_{3}$ specking } & \multirow{2}{*}{$\begin{array}{l}Y_{2} \text { Thermal } \\
\text { shock }\end{array}$} & \multirow{2}{*}{$\begin{array}{c}\mathrm{Y}_{1} \\
\text { Autoclave }\end{array}$} & \multirow[b]{2}{*}{$x_{1}$} & \multirow[b]{2}{*}{$x_{2}$} & \multirow[b]{2}{*}{$x_{3}$} & \multirow[b]{2}{*}{ RUN } \\
\hline & $\mathrm{K}_{2} \mathrm{MnO}_{4}$ & $\begin{array}{c}\text { Methylene } \\
\text { blue }\end{array}$ & & & & & & \\
\hline 4 & Class 3 & Class 3 & acceptable & unacceptable & 30 & $1100^{\circ} \mathrm{C}$ & $x<37$ & 1 \\
\hline 4 & Class 3 & Class 3 & unacceptable & unacceptable & 30 & $1100^{\circ} \mathrm{C}$ & $44<X<37$ & 2 \\
\hline 3 & Class 3 & Class 3 & unacceptable & unacceptable & 30 & $1150^{\circ} \mathrm{C}$ & $x<37$ & 3 \\
\hline 5 & Class 2 & Class 1 & acceptable & acceptable & 30 & $1150^{\circ} \mathrm{C}$ & $44<X<37$ & 4 \\
\hline 4 & Class 2 & Class 1 & acceptable & acceptable & 120 & $1100^{\circ} \mathrm{C}$ & $x<37$ & 5 \\
\hline 5 & Class 1 & Class 1 & acceptable & acceptable & 120 & $1100^{\circ} \mathrm{C}$ & $44<x<37$ & 6 \\
\hline 4 & Class 2 & Class 1 & acceptable & acceptable & 120 & $1150^{\circ} \mathrm{C}$ & $x<37$ & 7 \\
\hline 6 & Class 1 & Class 1 & acceptable & acceptable & 120 & $1150^{\circ} \mathrm{C}$ & $44<x<37$ & 8 \\
\hline
\end{tabular}

\section{Table 8}

Calculation of the main and interaction coefficients

\begin{tabular}{c|c|c|c|c|c|c|c|c}
\hline $\mathbf{a}_{\mathbf{0}}$ & $\mathbf{a}_{\mathbf{1}}$ & $\mathbf{a}_{\mathbf{2}}$ & $\mathbf{a}_{\mathbf{3}}$ & $\mathbf{a}_{\mathbf{1 2}}$ & $\mathbf{a}_{\mathbf{1 3}}$ & $\mathbf{a}_{\mathbf{2 3}}$ & $\mathbf{a}_{\mathbf{1 2 3}}$ & 2SE \\
\hline 4.37 & 0.62 & 0.125 & 0.3750 & 0.375 & 0.125 & 0.125 & -0.125 & 0.58 \\
\hline
\end{tabular}


Table 9

Analysis of variance with confidence level 90\% ( $F=4.5448)$

\begin{tabular}{|c|c|c|c|c|c|c|c|}
\hline Run & Factors & $\begin{array}{l}\text { Freedom } \\
\text { degree }\end{array}$ & Sum of square & Variance & $\mathbf{F}$ & $\begin{array}{c}\text { Purity } \\
\text { Variance }\end{array}$ & $\begin{array}{c}\text { Participation } \\
\text { percent }\end{array}$ \\
\hline 1 & PS & 1 & 3.125 & & 25 & 3 & 51.063 \\
\hline 2 & Temp & (1) & $(0.125)$ & & & & 0.000 \\
\hline 3 & PS $\times$ temp & 1 & 1.125 & 1.125 & 9 & 1 & 17.021 \\
\hline 4 & time & 1 & 1.125 & 1.125 & 9 & 1 & 17.021 \\
\hline \multirow[t]{3}{*}{6} & temp $\times$ time & (1) & & & \multicolumn{2}{|c|}{ POOLED (CL=65.03\%) } & 0.000 \\
\hline & error & 4 & 0.5 & 0.125 & & & 14.895 \\
\hline & Total & 7 & 5.875 & & & & $100.00 \%$ \\
\hline
\end{tabular}

\section{Table 10}

Analysis of variance with confidence level $99 \%(F=3.7760)$

\begin{tabular}{|c|c|c|c|c|c|c|c|}
\hline Run & Factors & $\begin{array}{c}\text { Freedom } \\
\text { degree }\end{array}$ & Sum of square & Variance & $\mathbf{F}$ & $\begin{array}{c}\text { Purity } \\
\text { Variance }\end{array}$ & $\begin{array}{c}\text { Participation } \\
\text { percent }\end{array}$ \\
\hline 1 & PS & 1 & 3.125 & 3.125 & 25 & 3 & 51.063 \\
\hline 2 & TEM & (1) & $(0.125)$ & & \multicolumn{2}{|c|}{ POOLED (CL=61.56\%) } & 0.000 \\
\hline 3 & PS $\times$ TEM & (1) & $(1.125)$ & & \multicolumn{2}{|c|}{ POOLED (CL=97.04\%) } & 0.000 \\
\hline 4 & $\mathrm{TE}$ & (1) & $(1.125)$ & & \multicolumn{2}{|c|}{ POOLED (CL=97.77\%) } & 0.000 \\
\hline 6 & TEM $\times$ TE & (1) & $(0.125)$ & & \multicolumn{2}{|c|}{ POOLED (CL=65.03\%) } & 0.000 \\
\hline & error & 6 & 2.750 & 0.458 & & & 48.937 \\
\hline & Total & 7 & 5.875 & & & & $100.00 \%$ \\
\hline
\end{tabular}

is the best sample according to existing standard of floor tile. The analysis of variance with two confidence levels of 90 and $99 \%$ are shown in Tables 9 and 10.

According to the analysis of variance with confidence level of $90 \%$, those parameters which are bolded are significant. By increasing confidence level, the number of effective factors was decreased and the particle size of glaze slurry is only significant parameter. In addition, selection other factors are not required.

The simplest method to obtain the optimized levels is drawing chart of the average of responses. The effect of low and high levels of variables in hardness of glaze obtained using statistical software was shown in Figure 2. Table 11 suggests the optimized levels of variables.

\section{Table 11}

Proposed levels of factors in optimization condition

\begin{tabular}{c|c}
\hline Factor & Proposed level \\
\hline TE & 120 \\
\hline TEM & $1150^{\circ} \mathrm{C}$ \\
\hline PS & $44<X<37$ \\
\hline
\end{tabular}

Table 11 and Figure 2 confirm each other. This shows that the examined factors, selected in high levels, i.e.; hardness, is in the highest level in terms of the quality measure. Therefore this sample was prepared as the optimized conditions of eighth experiments and can be regarded as the proposed sample.

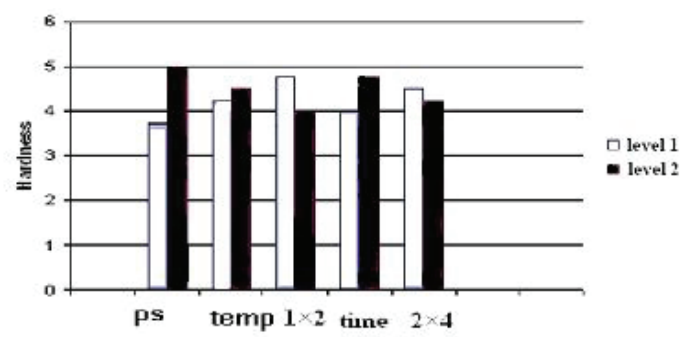

» Figure 2: The effect of levels of parameters on floor tile hardness

\section{Conclusions}

The factorial design analysis revealed that if $\left(\mathrm{a}_{1}>2 \mathrm{SE}\right)$, the influence of the particle size of glaze slurry (variable $X_{1}$ ) in hardness of glaze has been significant. The samples 1-3 were not acceptable according to the existing standards of floor tile so they were eliminated. Among of the residual samples, the samples 5 and 7 with low level of particle size were eliminated. Therefore, the appropriate sample should be selected from three residual samples (4, 6 and 8). The sample 4 with high level in particle size and temperature of sintering is the best sample according to the standard of floor tile. 
Based on the Taguchi method and according to the analysis of variance with a confidence level of $90 \%, F$ is equal to 4.5448. Comparing this $F$ with the critical $F$ shown above the Table 10, the influence of variables is obvious. So the parameters which are bolded are significant. With a rise in confidence level to $99 \%$, the numbers of effective factors were decreased. Moreover, the particle size of slurry is the only significant parameter.

\section{References}

Anufrik, S. S., Kurian, N. N., Zhukova, I. I., Znosko, K. F. \& Belkov, M. V. (2016) Chemical composition of ceramic tile glazes. Journal of Applied Spectroscopy. 83 (5), 764-770. Available from: doi: 10.1007/ s10812-016-0360-8 [Accessed 15th May 2017].

Burleson, M. (2003) The Ceramic Glaze Handbook. New York, Lark books.

Castela, A. O., Fonseca, A. \& Mantas, P. (2010) Development of coloured glazes for tile applications using Taguchi's method. Journal of the European Ceramic Society. 30 (12), 24512455. Available from: doi: 10.1016/j.jeurceramsoc.2010.05.016 [Accessed 10th May 2017].

Chen, K. C., Wee, H. M., Wang, S. L. \& Wang, J. H (2015) Caracteristic analysis of sintered glaze on copper metal material surface. International Journal of New Technology and Research. 1 (5), 59-62. Available from: https://www.ijntr.org/download_data/ IJNTR01050027.pdf [Accessed 12th May 2017].

Feinberg, M. (1996) La Validation Des Méthodes D’analyse. Paris, Masson.
Ghosh, S. (ed.) (1990) Statistical Design and Analysis of Industrial Experiments. Statistical, textbooks and monographs. New York, Marcel Dekker.

Mukerjee, R. \& Wu, J. C. F. (2006) A Modern Theory of Factorial Design: Springer Series in Statistics. New York, Springer.

Reddy, K. R. \& Asadi, S. S. (2011) An experimental study for identification of suitable low cost alternative flux material in manufacturing of red body ceramic glazed tiles: a model study. Material Science Research India. 8 (2), 289-295. Available from: http://www. materialsciencejournal. org/?p=2653 [Accessed 12th May 2017].

Ross, P. J. (1995) Taguchi Technique for Quality Engineering. 2nd ed. New York, McGraw-Hill.

Roy, R. K. (2001) Design of Experiment Using the Taguchi Approach: 16 Steps to Product and Process Improvement. New York, Wiley.

Sharda, A. \& Kumar, S. (2015) Experimental investigation of $U$ value of double-glazed window with inter-pane blinds using Taguchi techniques. Energy Efficiency. 9 (5). Available from: doi: 10.1007/ s12053-015-9413-8 [Accessed 10th May 2017].

Smith, M. J. (2015) Statistical Analysis Handbook: A Comprehensive Handbook of Statistical Concepts, Techniques and Software Tools. Available from: http://www.statsref.com/HTML/index.html?design_of_experiments.html [Accessed 12th June 2016].

Vari, A. (2000) Glazing and Decoration Ceramic Tiles. Rome, S.A.L.A.

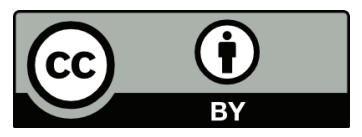

(C) 2017 Authors. Published by the University of Novi Sad, Faculty of Technical Sciences, Department of Graphic Engineering and Design. This article is an open access article distributed under the terms and conditions of the Creative Commons Attribution license 3.0 Serbia (http://creativecommons.org/licenses/by/3.0/rs/). 